\title{
Ventrikular Takikardia Refrakter Pada STEMI \& Stroke
}

Tommy Daindes ${ }^{1}$, Hauda El Rasyid²

\begin{abstract}
Abstrak
Pasien STEMI memiliki resiko 4 kali lebih tinggi untuk mengalami aritmia ventrikel yang umumnya terjadi dalam 48 jam pertama setelah onset. Dengan kondisi penyakit penyerta berupa stroke dengan skor severitas berat atau stroke hemoragik, intervensi koroner perkutan (IKP) atau pemberian obat - obatan anti trombotik tidak dapat dilakukan pada fase - fase awal. Optimalisasi obat - obatan anti-iskemik dan anti-aritmia menjadi strategi utama. Aritmia sendiri cukup sering dijumpai selama fase akut stroke, namun mekanisme aritmia ventrikel pada sindroma koroner akut (SKA) dan fase akut stroke masih diperdebatkan. Terlalu absurd jika hanya memikirkan kelainan jantung sebagai penyebab aritmia, mengabaikan kejadian neurologis yang juga sedang terjadi. Beberapa penelitian menunjukkan STEMI \& stroke akut dapat memicu timbulnya aritmia ventrikel melalui mekanisme yang berbeda. Laporan Kasus ini dibuat untuk memberikan contoh praktikal dari ilustrasi diatas. Pada kasus ini pasien memiliki 2 entitas penyakit akut disaat bersamaan, yakni STEMI dan stroke. Pasien juga mengalami aritmia ventrikular yang refrakter. Pada akhirnya, dapat ditarik kesimpulan bahwa aritmia yang timbul bukan hanya diakibatkan oleh kelainan kardiovaskular semata, yang lebih umum dipahami, tetapi juga sebagai komplikasi dari kelainan akut neurologis. Diperlukan penanganan multi-disiplin ilmu dan komperhensif untuk optimalisasi manajemen pasien ini.
\end{abstract}

Kata kunci: ventricular takikardia, STEMI, stroke

\begin{abstract}
Patients with ST elevation myocardial infarction (STEMI) have a 4-fold higher risk for ventricular arrhythmia (VA), mostly occurred in first 48 hours. In concomitant condition with acute stroke especially those with high stroke scoring or haemorragic stroke, percutaneous coronary intervention (PCI) can not be performed early and anti thrombotic therapy can not be given. Optimal anti ischemic and anti arrhythmic therapy are the most important strategy in this case. Meanwhile, cardiac arrhythmias following acute stroke is not rare but mechanisms of VA in acute coronary syndrome (ACS) concomitan with acute phase of stroke still debated. It is unlikely to assume that underlying cardiac diseases are the only cause of arrhythmia and cardiac damage after an acute stroke, ignoring neurologic event itself. Studies showed both STEMI and acute stroke could lead to ventricular arrhythmia with different mechanism. Present case report was made as practical example of previous illustration. In this case, patient with 2 acute illneses at the same time, STEMI and stroke. Patient also suffered refractory ventricular arrhythmia. At the end, we can conclude that arrhythmia was not only caused by cardiovascular problem, as usual understandings, but also due to complication of acute neurologic event. Multi-discipline management was needed to optimalize patient's outcome.
\end{abstract}

Keywords: ventricular tachycardia, STEMI, stroke

Affiliasi penulis : 1.PPDS IImu Penyakit Jantung dan Pembuluh Darah 2. Bagian Kardiologi dan Kedokteran Vaskular Fakultas Kedokteran UNAND / RSUP Dr. M. Djamil

Korespondensi : Jalan Perintis Kemerdekaan Padang kardiologiunand@yahoo.com Telp: 075136494

\section{PENDAHULUAN}

Sembilan puluh persen aritmia ventrikel pada STEMI terjadi dalam 48 jam pertama, sementara pada NSTEMI $60 \%$ aritmia ventrikel terjadi setelah 48 jam. Pada periode awal paska infark miokard, insiden nonsustained VT mencapai $13 \%$, sustained VT 3\%, dan VF $3 \%$. Pada 2 studi (GUSTO IIB dan GUTSO III) aritmia ventrikel yang berkelanjutan (sustained) terjadi pada $6 \%$ pasien sindrom koroner akut (SKA). Insidensi akan jauh meningkat pada pasien - pasien yang memiliki kelainan bawaan, seperti sindroma long-QT (LQTS), sindroma short-QT, sindroma Wolff-Parkinson-White, sindroma Brugada, arrhythmogenic right ventricular cardiomyopathy, kardiomiopati hipertrofik, catecholaminergic polymorphic ventricular tachycardia (CPVT) serta varian genetik lainnya. ${ }^{1,2}$

Pada sisi lain, komplikasi kardiak cukup sering terjadi setelah stroke akut. EKG yang abnormal dan aritmia teridentifikasi pada $50-70 \%$ pasien stroke akut. Pola abnormalitas bervariasi mulai dari gelombang $\mathrm{T}$ yang abnormal, pemanjangan interval $Q T$, sampai aritmia maligna seperti ventrikular fibrilasi (VF) dan ventrikular takikardia (VT). Penjelasan untuk tingginya frekuensi aritmia pada pasien stroke disebabkan kadar katekolamin yang meningkat, ketidakseimbangan sistem otonom jantung dan penyakit jantung yang mendasari (tanpa ada hubungan langsung dengan stroke sendiri). Menjadi penting untuk mengidentifikasi apakah ada korelasi langsung antara kelainan EKG, aritmia dan stroke akut, atau hanya koinsiden semata walaupun seringkali sulit untuk membedakan hal tersebut karena faktor resiko untuk penyakit jantung koroner seringkali juga dijumpai pada pasien stroke. ${ }^{2}$

Laporan kasus ini disusun untuk memahami mekanisme dan penatalaksanaan aritmia ventrikel pada pasien STEMI dan stroke akut.

\section{LAPORAN KASUS}

Seorang pasien laki - laki berusia 38 tahun dikonsulkan dengan diagnosa penurunan kesadaran disertai hemiparese sinistra, parese N VII \& XII ec stroke kardioembolik, sinus aritmia dan VES bigemini. Dari alloanamnesa diketahui bahwa penurunan kesadaran dialami pasien sejak 2 jam sebelum masuk RS saat pasien sedang beraktifitas dan diawali dengan 
kelemahan anggota gerak sebelah kiri. Nyeri dada khas infark juga dikeluhkan pasien sejak 2 hari sebelum masuk RS tapi tidak mendapat pengobatan apapun. Tidak ada keluhan kejang, sesak nafas dan berdebar debar. Faktor resiko untuk penyakit jantung koroner adalah perokok aktif (1-2 bungkus/hari) selama $>20$ tahun.

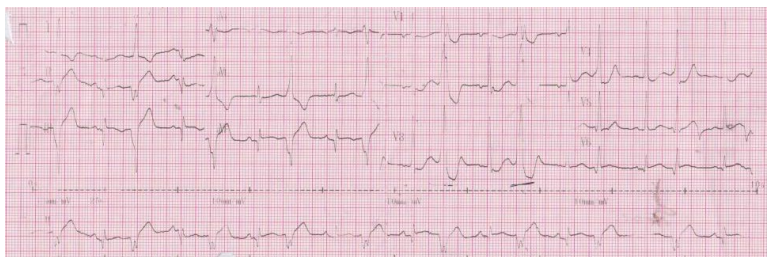

Gambar 1. EKG ke-1 di IGD

Pasien tampak sakit berat, somnolen, tekanan darah 120/70 mmhg, frekuensi nadi 110 kali/menit, frekuensi nafas $22 \mathrm{kali} / \mathrm{menit}$. Pupil anisokor, JVP 5$2 \mathrm{cmH} 2 \mathrm{O}$ bunyi jantung cepat dan reguler, tidak ada murmur ataupun gallop, suara nafas bronkovesikuler dengan ronki kasar di lapangan paru kanan dan kelemahan anggota gerak sebelah kiri. Elektrokardiografi menunjukkan sinus takikardi dengan VES bigemini, laju jantung $110 \mathrm{x} /$ menit, aksis deviasi kekiri, interval PR 0.12", durasi QRS 0.04", elevasi segmen ST disertai gelombang $Q$ patologis di II, III, aVF, depresi segmen ST di V1-V4, tidak ada hipertrofi ventrikel kanan ataupun kiri (Gambar 1). Foto torak menunjukkan kardiomegali ringan (CTR 58\%), segmen aorta dan segmen pulmonal normal, pinggang jantung (+) dan tampak infiltrat di lapangan paru kanan.

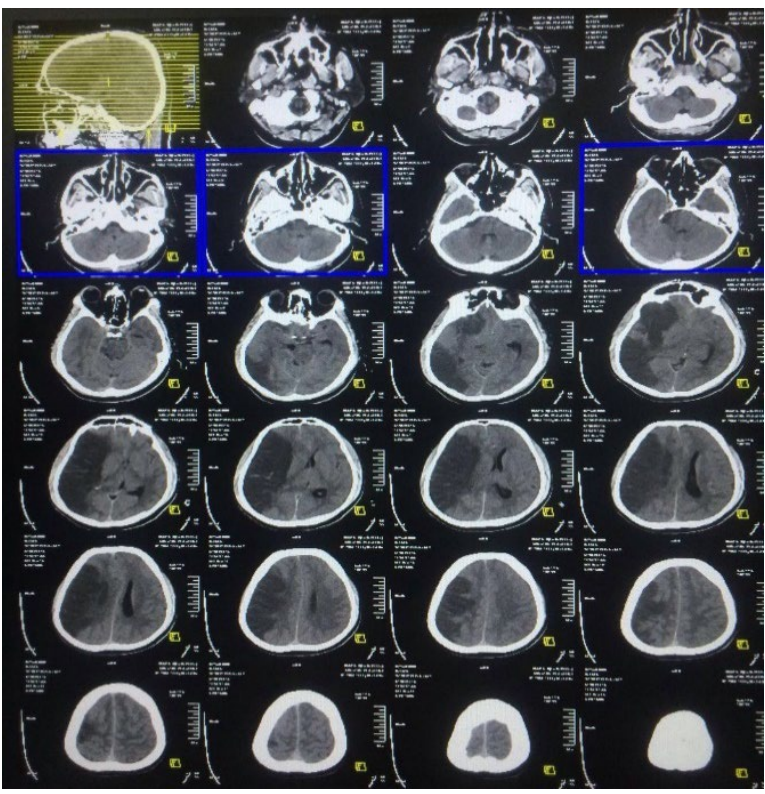

Gambar 2. CT scan otak di IGD

Pada CT scan otak tampak lesi hipodens luas di temporoparietal kanan, penyempitan sulcii di hemisfer kanan, midline masih di tengah, disimpulkan sebagai suatu infark serebri luas regio temporoparietal kanan (Gambar 2). Monitor EKG menunjukkan ventricular tachycardia (VT) tanpa ada tanda - tanda ketidakstabilan klinis (Gambar 3). Pasien kemudian didiagnosa sebagai STEMI inferior akut late onset, VT stabil, stroke kardioembolik akut serta community acquired pneumonia (CAP). Pasien dirawat di bangsal neurologi dan mendapat terapi IVFD Asering 1 kolf/24 jam, citicolin 2x1 gr dan protokol drip mannitol. Dari bagian kardiologi pasien mendapat terapi ASA $80 \mathrm{mg}$, clopidogrel $75 \mathrm{mg}$, fondaparinux $2.5 \mathrm{mg}$, atorvastatin $40 \mathrm{mg}$, amiodarone bolus iv $150 \mathrm{mg}$, dilanjutkan drip $360 \mathrm{mg} / 6$ jam dan 540mg/18 jam serta cefoperazon $2 \times 1 \mathrm{gr}$.

Pada perawatan hari kedua tingkat kesadaran pasien menurun (koma) dan lateralisasi menjadi semakin jelas. Tekanan darah turun berkisar 90100/50-60 mmhg dan EKG menunjukkan VT. Pasien didiagnosa mengalami stroke hemoragik akut sehingga anti trombotik dihentikan. Pasien mendapat lidocain drip dan tablet amiodarone $3 \times 200 \mathrm{mg}$.

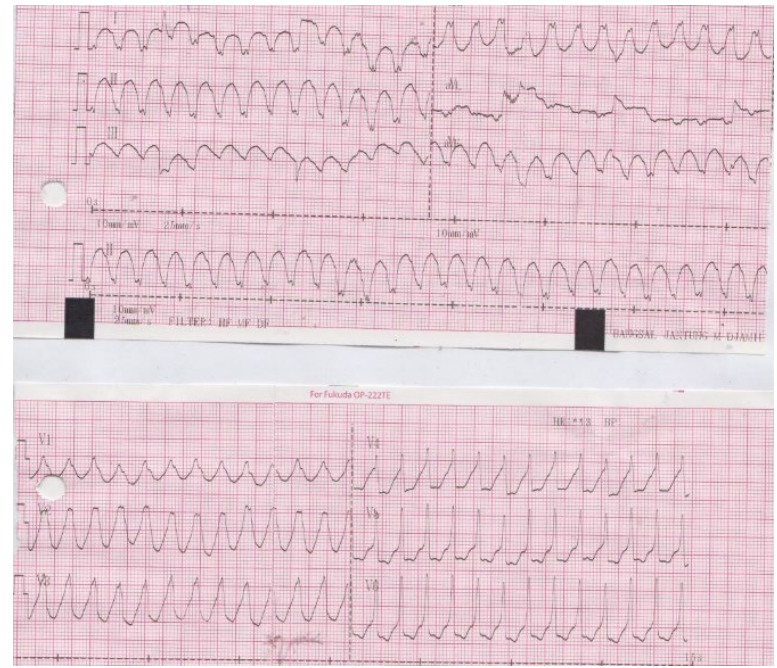

Gambar 3. EKG ke-2 di IGD

Perawatan hari ke 3 dan seterusnya kondisi pasien menurun. Drip norpeinefrin diberikan. EKG masih menunjukkan VT. Pada hari ke-5 pasien pindah ke bangsal jantung. Monitor masih VT masih berlanjut (Gambar 4). Kardioversi elektrik atau pemasangan pacu jantung sementara tidak disetujui keluarga. Ekokardiografi menunjukkan fungsi sistolik LV baik (EF $60 \%$-eyeballed), hipokinetik di mid dan basal inferoseptal dan tidak tampak trombus intrakardiak.

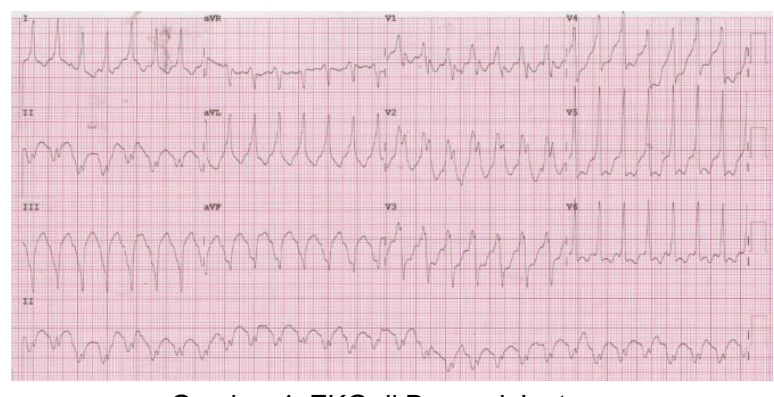

Gambar 4: EKG di Bangsal Jantung

Hari rawatan ke 6 (hari kedua di jantung) pasien mengalami apnoe, EKG monitor menunjukkan irama VT, denyut nadi tidak teraba. Resusitasi jantung paru (RJP) tidak dilakukan karena pasien sudah dalam status "do not resuscitate". EKG berubah menjadi accelerated junctional rythm, pulseless electrical 
activity (PEA). Setelah kurang lebih 20 menit, pasien dinyatakan meninggal dunia.

\section{DISKUSI}

Penyakit jantung koroner serta faktor resikonya sering dijumpai pada pasien stroke. STEMI \& stroke dapat menyebabkan aritmia ventrikel melalui mekanisme yang berbeda. Pada kasus ini STEMI diduga terjadi sebelum stroke berdasarkan aanamnesa adanya nyeri dada khas infark sebelum keluhan stroke walaupun EKG baru dilakkan setelah stroke terjadi.

Mekanisme aritmia ventrikel pada pasien STEMI bervariasi tergantung pada penyakit yang mendasari (Gambar 3), seperti mekanisme reentry intramural pada kondisi iskemia dan triggered activity pada keadaan reperfusi. Karakteristik pasien - pasien yang mengalami arimia ventrikel berkelanjutan (sustained) pada hari - hari pertama setelah infark miokard dapat dibedakan sebagai berikut: 2,3

- Late presenters (pasien yang terlambat mendapat terapi reperfusi)

- Pasien dengan tidak menjalani revaskularisasi atau baru menjalani revaskularisasi parsial.

- Pasien yang sudah memiliki substrat aritmogenik sebelum kejadian infark miokard akibat adanya infark lama atau kelainan elektrofisiologis bawaan. (Gambar 5)

Pasien pasien ini VT terjadi pada stroke sehingga tidak memungkinkan untuk menjalani revaskularisasi segera.

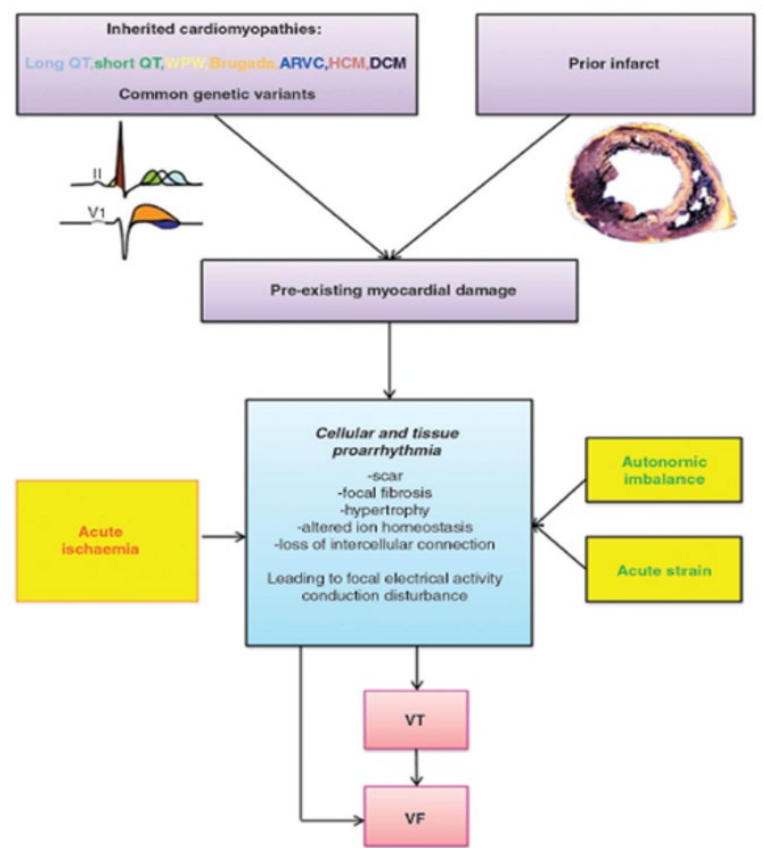

Gambar 5. Mekanisme Aritmia pada Sindrom Koroner Akut $^{1}$

Pada stroke akut ketidakseimbangan kontrol otonom sentral bertanggung jawab terhadap kejadian VT. Gambar 6 \& Tabel 1 memperlihatkan hal-hal yang sering terjadi pada stroke akut yang dapat menyebabkan aritmia. ${ }^{3,4,6}$

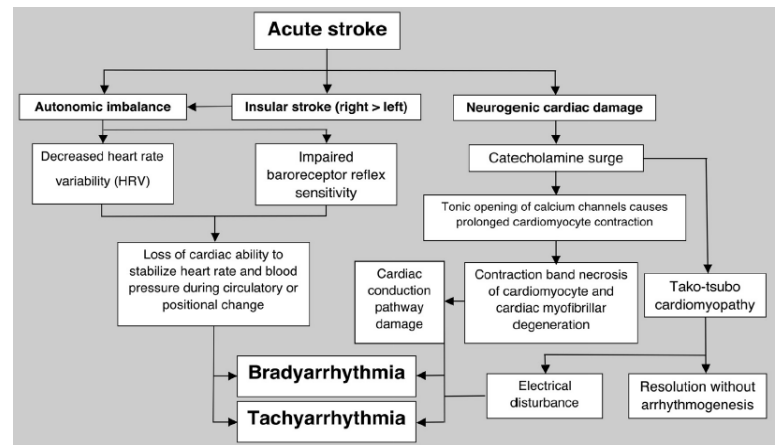

Gambar 6. Mekanisme Aritmia pada Stroke Akut ${ }^{6}$

Tabel 1. Insiden Aritmia Setelah Stroke Akut ${ }^{5}$

\begin{tabular}{lcc} 
& Arrhythmia & No. $(\%)$ \\
\hline Tachycardia & Sustained VT & 0 \\
& Nonsustained VT & $6(1.2 \%)$ \\
& Ventricular ectopy & $7(1.4 \%)$ \\
& Atrial fibrillation & $57(11 \%)$ \\
& Atrial flutter & $1(0.20 \%)$ \\
Bradycardia & Focal atrial tachycardia & $15(3.0 \%)$ \\
& Undetermined SVT & $10(2.0 \%)$ \\
& Asystole/ SA block & $8(1.6 \%)$ \\
& AV block 에 & $10(2.0 \%)$ \\
& AV block ${ }^{\circ}$ III & $1(0.20 \%)$ \\
& Atrial fibrillation & $24(4.8 \%)$
\end{tabular}

Aritmia lebih sering terjadi pada pasien yang sudah memiliki komorbid kardiak sebelumnya, seperti usia lanjut, hipertensi dan diabetes mellitus, keparahan defisit neurologis akan memperberat aritmia. Skor NIHSS digunakan untuk memprediksi derajat keparahan stroke. Rerata skor NIHSS adalah 5.5 pada pasien stroke dengan aritmia sementara pasien tanpa aritmia rerata skor $2.4,5$

Skor NIHSS yang lebih tinggi juga berkorelasi dengan gangguan kontrol otonom kardiovaskuler. Hal ini ditandai dengan hilangnya modulasi otonom secara umum, penurunan tonus parasimpatis, gangguan sensitifitas barorefleks serta pergeseran dominasi simpatis. Sehingga skor NIHSS awal saat pasien masuk dapat digunakan untuk stratifikasi pemantauan yang dibutuhkan pasien setelah 24 jam pertama. Pasien pada laporan kasus ini sendiri memiliki skkor NIHSS 16 (stroke menengah-berat). ${ }^{4}$

Tatalaksana awal VT tanpa nadi NF adalah defibrilasi. Kardioversi elektrik dilakukan jika terjadi VT dengan nadi disertai tanda-tanda ketidak stabilan. Obat-obat anti-aritmia (AAD) dapat dipertimbangkan. Jika iskemia diduga bertanggungjawab atas kejadian aritmia, reperfusi segera menjadi pilihan utama. Pada pasien ini $\mathrm{PCl}$ tidak bisa dilakukan karena stroke yang terjadi mempunyai derajat NIHSS menengah berat yang kemudian diduga berubah menjadi hemoragik. ${ }^{3,4}$

Penggunaan beta blocker pada fase awal SKA terbukti menurunkan mortalitas dan insidensi aritmia ventrikel. Juga koreksi hipomagnesemia dan hipokalemia, karena adanya potensi kontribusi ketidakseimbangan elektrolit ini terhadap kejadian aritmia ventrikel. Terapi statin juga menurunkan mortalitas pasien-pasien PJK sehingga direkomendasikan sebagai terapi rutin. Sebagai tambahan, terapi statin awal dan intensif telah 
dilaporkan menurunkan insidensi premature ventricular complexes (PVCs) dan non-sustained VA. ${ }^{2,4}$

Lidokain sebagai anti-aritmia kelas I dapat menurunkan insiden aritmia ventrikel yang berhubungan dengan iskemia miokard, walaupun tidak ada manfaat terhadap mortalitas fase awal. Pada sisi lain, terapi profilaksis dengan lidokain setelah henti jantung dan resusitasi yang sukses menunjukkan manfaat terhadap rekurensi aritmia ventrikel dan mortalitas. Studi terbaru dari GUSTO IIB dan GUSTO III menunjukkan bahwa lidokain menurunan mortalitas awal pasien - pasien VT/VF setelah infark miokard akut (IMA) dan memiliki efek netral pada mortalitas 30 hari. Dengan mempertimbangkan segala manfaat dan efek samping, lidokain disarankan sebagai pilihan antiaritmia untuk penatalaksanaan akut VT/VF pada SKA. 2,3

Amiodaron merupakan anti-aritmia kelas III dengan berbagai properti elektrofisiologis tambahan. Ketika dibutuhkan anti-aritmia pada pasien - pasien dengan kelainan struktural jantung yang berat, setelah menimbang efficacy-to-risk profile, amiodaron menjadi pilihan utama. Dua studi terandomisasi (European Amiodarone Myocardial Infarction Trial dan Canadian Amiodarone Myocardial Infarction Trial), mengevaluasi penggunaan amiodaron sebagai prevensi utama pada pasien post IMA. Hasilnya menunjukkan insiden mortalitas dan aritmia lebih rendah pada pasien yang mendapat terapi amiodaron dibanding mereka diberi plasebo, namun hanya jika pasien - pasien tersebut juga mendapat beta blocker. Tidak ada manfaat pemberian amiodaron jika pasien tidak mendapat terapi beta blocker. 2,3

Pada konteks SKA, terapi amiodaron, dibandingkan dengan lidokain, secara retrospektif meningkatkan mortalitas baik jangka pendek maupun jangka panjang. Pada sisi lain, pada keadaan henti jantung diluar rumah sakit, amiodaron pada pasien VF refrakter diasosiasikan dengan angka survival yang lebih tinggi dibandingkan lidokain. Amiodaron dapat diberikan untuk menekan (iv atau oral) ataupun mencegah (oral) rekurensi aritmia bersamaan dengan beta blocker. Penatalaksanaan aritmia ventrikel pada pasien SKA diilustrasikan sebagai berikut: ${ }^{3}$

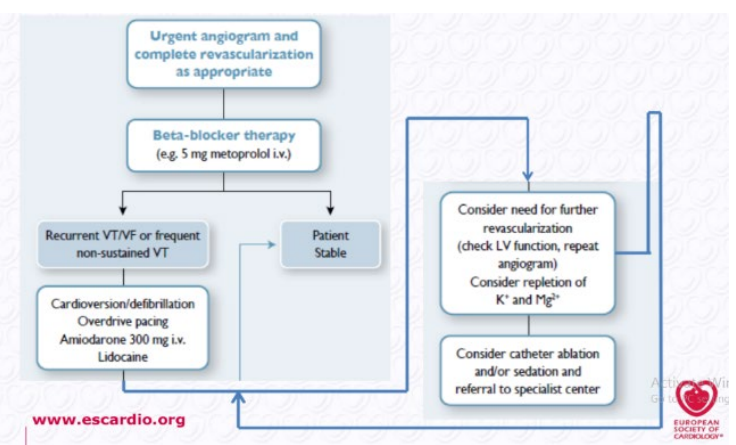

Gambar 7. Alur Penatalaksanaan Pasien dengan sustained VT dan SKA ${ }^{3}$

Sementara untuk pemilihan anti-aritmia pada pasien dengan stroke, penggunaan beta blocker memiliki manfaat dengan mekanisme antagonis terhadap overaktifitas dari kontrol simpatis. Penatalaksanaan aritmia setelah stroke akut dirangkum sebagai berikut: 5,6

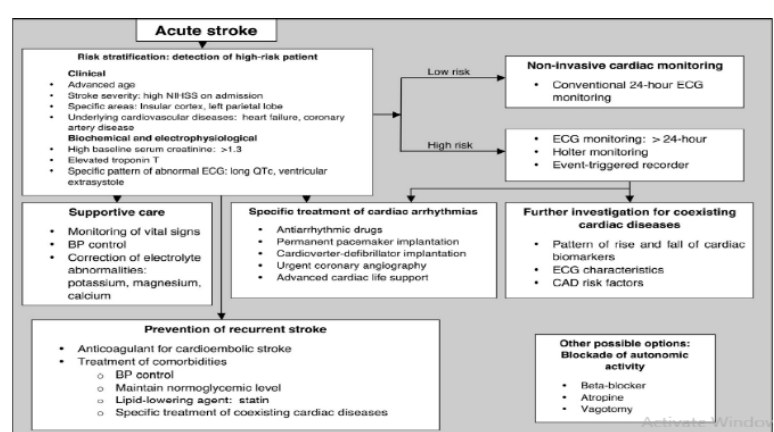

Gambar 8. Tinjauan Skematik Penatalaksanaan Aritmia Setelah Stroke Akut ${ }^{6}$

Pada pasien ini, primary $\mathrm{PCl}$ tidak dapat dilakukan karena merupakan kontraindikasi pada pasien stroke akut dan sayangnya pasien juga tidak mendapat terapi beta blocker yang adekuat (metoprolol iv) karena ketidaktersediaan obat. Keluarga juga tidak setuju untuk kardioversi atau pemasangan pacu jantung sementara agar overdrive pacing dapat dilakukan. Penatalaksanaan dilanjutkan dengan pemberian drip amiodaron dan lidokain. Terapi tersebut tidak memberikan respon yang adekuat karena episode VT berlanjut sampai 7 hari. Pengecualian terhadap terapi akut yang tidak adekuat, kami memiliki hipotesis bahwa VT yang berkelanjutan (sustained) juga diakibatkan oleh adanya kontribusi dari kelainan intrakranial (stroke akut), yang menyebabkan kemungkinan konversi VT menjadi lebih kecil.

Kateter ablasi untuk aritmia ventrikel selama fase akut SKA jarang dilakukan, kebanyakan dilakukan pada aritmia ventrikel yang menetap setelah fase akut SKA terlewati. Namun pada keadaan aritmia ventrikel yang refkrakter dengan obat - obatan, ablasi kateter setelah perbaikan kondisi iskemia dapat dilakukan. Karena keadaan hemodinamik pasien - pasien ini cenderung tidak stabil, prosedur ini berisiko tinggi dengan angka morbiditas dan mortalitas yang tinggi. 7,8

Pada aritmia ventrikel berkelanjutan dapat dipertimbangkan pemasangan implanted cardiac defibrillator (ICD) sesuai panduan berikut: ${ }^{9}$

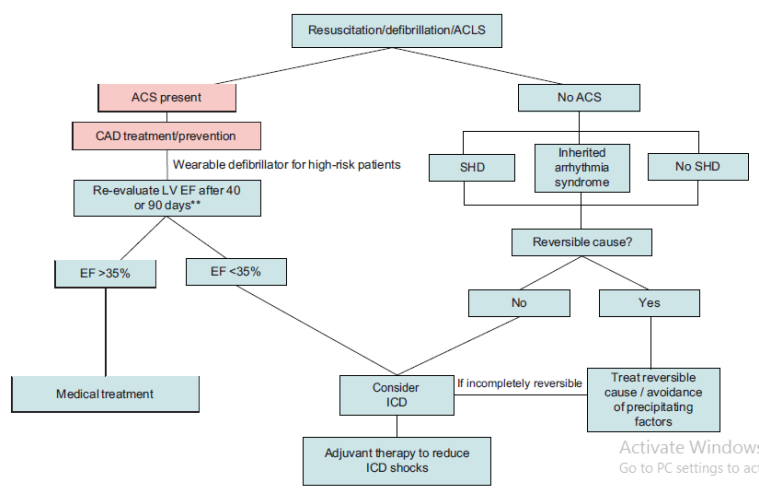

Gambar 9: Tinjauan Skematik Penatalaksanaan Aritmia Paska SKA ${ }^{9}$ 


\section{SIMPULAN}

Telah dilaporkan satu kasus aritmia ventrikel refrakter pada pasien stroke derajat menengah berat yang berkembang menjadi stroke hemoragik dan STEMI late onset. Aritmia yang terjadi pada kasus ini sangat mungkin disebabkan STEMI dan juga stroke, yang memperbesar kemungkinan terjadinya aritmia ventrikel. Penatalaksanaan kasus ini menjadi tidak optimal karena $\mathrm{PCl}$ tidak dapat dilakukan, tidak tersedianya obat-obat yang adekuat serta ketidaksiapan keluarga untuk bekerjasama dengan tim medis.

Beta blocker intravena, amiodaraon intra vena atau lidokain intravena merupakan obat-obat antiaritmia yang dapat diberikan pada pasien stroke hemoragik, STEMI dan aritmia ventrikel, selain tentunya kardioversi elektrik dan overdrive pacu jantung sementara. ICD dapat dipertimbangkan sebagai penatalaksanaan jangka panjang setelah fase akut infark miokard sudah terlewati.

\section{DAFTAR PUSTAKA}

1. Gorenek B, Blomström-Lundqvist C, BrugadaTerradellas J, Camm AJ, Hindricks G, Huber K, et al. Cardiac Arrhythmias in ACS: Position Paper from the Joint EHRA, ACCA, and EAPCI Task Force. Journal of Eurolntervention. 2014; 10(2):922-926.

2. Das B, Mishra TK. Prevention and Management of Arrhythmias in Acute Myocardial Infarction. International Journal of Contemporary Medical Research. 2016; 3(5):1401-1405.

3. Priori SG, Blomstrom-Lundqvist $C$, Mazzanti A, Bloma N, Borggrefe M, Camm J, et al. 2015 ESC Guidelines for the management of patients with ventricular arrhythmias and the prevention of sudden cardiac death, European Heart Journal. 2015; 36:2793-2867.

4. Pride YB, Appelbaum E, Lord EE, Sloan S, Cannon $\mathrm{CP}$, et al. Relation between myocardial infarct size and ventricular tachyarrhythmia among patients with preserved left ventricular ejection fraction following fibrinolytic therapy for ST-segment elevation myocardial infarc-tion. American Journal of Cardiology. 2009; 104:475-9.

5. Kallmünzer B, Breuer L, Kahl N, Bobinger B, RaazSchrauder, Huttner B, et al. Serious Cardiac Arrhythmias After Stroke. American Stroke Journal. 2012:43:2892-2897.

6. Ruthirago $D$, Julayanont $P$, Tantrachoti $P$, Jongyeol K, Nugent K, Cardiac Arrhythmias \& Abnormal ECGs after Acute Stroke, American Journal of The Medical Sciences. 2016; 351(1):112-118.

7. Soros $P$, Hachinski V. Cardiovascular and neurological causes of sudden death after ischaemic stroke. Lancet Neurology. 2012; 11:179-188.

8. Rincon F, Dhamoon M, Moon Y, Paik MC, BodenAlbala B, Homma S, et al. Stroke location and association with fatal cardiac outcomes: Northern
Manhattan Study (NOMAS). Stroke. 2008; 39:2425-2431.

9. Pedersen CT, Kay GN, Kalman J, Borggrefe M, Della-Bella P, Dickfeld T, et al, Expert Consensus on Ventricular Arrhythmias, EHRA/HRS/APHRS, Heart Rhythm. 2014; 11(10). 